\title{
Why Does Personalism Turn Towards Animal Ethics?
}

\author{
Alfred Marek Wierzbicki \\ The John Paul II Catholic University of Lublin (PL)
}

\begin{abstract}
The intellectual heritage of modernity needs rethinking. It is marked by radical humanism and implied by the ideas of Descartes and Kant above all, which introduces an unbridgeable gap between animals and human persons (nonhuman and human animals). Intuitive sensibility to the question of the welfare of nonhuman animals meets a theoretical ally in the rapidly growing knowledge on their subjectivity and makes us pose a questions about their ontological status. This context arouses a possibility of a turn to personalist ethics, yet not to its anthropocentric version implied by Kant, but to personalism conceived of as an instance of value ethics as exemplified by Antonio Rosmini and Karol Wojtyła (John Paul II).
\end{abstract}

Keywords: persons, animals, categorical imperative, value ethics, humanism, speciesism

\section{Humanism not Rejected but Supplemented}

Not infrequently have I encountered the objection that personalism, while elevating human beings, diminishes or belittles animals. I believe this objection to be only partially justified. In my presentation, I will attempt to demonstrate that personalism, conceived of as an outstanding and special instance of value ethics, postulates its own completion in the form of an insight into animal ethics. The reason is that the field of the moral "ought" is determined by two values: the person and life. Thus the radical hiatus between the value of a human being and the value of an animal being, presupposed in the ideas of the leading philosophers of modernity, cannot be rationally defended.

The humanism developed by modern philosophy, sometimes described as the anthropological breakthrough, has created an invigorating climate for the growth of the culture of human rights. Yet this project, focusing on the emancipation of the human-being and so eagerly advanced by the philosophers of the modern era, is accompanied by an aggravation of the fate of animals, degraded to the status of products, objects of consumption, and as a result of intensive breeding, subjected to suffering unknown in wildlife.

In my view, while Descartes and Kant are not to directly blame for the growing cruelty of humans towards animals, the humanist bias of those philosophers contributed unquestionably to the prevalence of the attitude of speciesism. The Cartesian concept of animals as automata meant that animals were, in theory, denied subjectivity, which in practice opened the way for human (thinking) beings (res cogitans) to dominate them completely. Likewise, in the Kantian ethics of the categorical imperative, the key argument for ethical deontologism rested on the understanding of the human person as an "end-in-itself." Kant would not allow spreading the limits of deontologism so that it would encompass other living beings, since he did not see how it might be possible to recognize "ends-in-themselves" in beings other than persons. In the ethics of moral autonomy, the intrinsic human

Alfred Marek Wierzbicki, Ph.D., professor, Faculty of Philosophy, The John Paul II Catholic University of Lublin (PL), Poland; main research field: Ethics. Email: a.wierzbicki@diecezja.lublin.pl. 
dignity is derived from the fact that subjects endowed with freedom are capable of making the moral law. Since animals do not formulate categorical imperatives, they cannot be subjects to them. The Kantian exclusion of animals from the bounds of moral duty is a consequence of the assumption that respect, kindness, and care are due only to beings capable of rationally commanding such attitudes to themselves as norms and of binding themselves with these norms through universal law which implies reciprocity. Needless to say, held by Kant, reciprocation of respect, kindness, or care may be only rarely expected of animals.

Modern humanism, including its crystallization in the philosophy of Immanuel Kant, which is open to a personalist interpretation, draws on the actual experience of the special position that the human being enjoys in the world. "Transcendence"-observes Karol Wojtyła, a personalist thinker whose ideas were deeply rooted in the modern "philosophy of the subject"-is "another name for the person." Still, we must stress, the anthropocentric bias of modern personalism has obscured the fact that human persons are not the only living beings in this world. It is at this point that the intellectual heritage of modernity needs a rethinking or amendment, which will make it possible for us to retain the essentially personalist sense of modern humanism and simultaneously purify it by removing the mark that the isolationism of the human species has left on it, leading to various forms of speciesism.

\section{The Subjectivity of the Human Persons and the Subjectivity of the Nonhuman Animals}

What we know about animal living today radically departs from what Descartes or Kant have to say about them. Animals can no longer be denied the status of subjects. Animal psychology has described the emotional and cognitive processes characteristic of them. We know that animals demonstrate cognitive and communicational skills and abilities. While the results of ethological research are sometimes ambivalent, showing both similarities and differences between non-human and human behaviors, it is a fact that manifestations of sympathy, friendship, care, and justice - phenomena to which we usually attribute moral value - may be empirically observed among animals.

The rigid and narrow categories of "subjectivity" and "morality," and the pillars on which the modern humanist philosophies have built the edifice of personalist moral exclusivism, begin to crack when confronted with the rich knowledge that a whole range of sciences provides on animal subjectivity and morality. Does this mean that we need to abandon the entire concept of the difference between human and animal existence? I believe it would be too radical a move, and one encumbered with another monistic tendency in the interpretation of being, a tendency in a way resembling what underlies the modern idea of treating animals as objects humans, can limitlessly subordinate to their goals.

At this point, we need to ask two fundamental questions: Does any instance of subjectivity mean that we are dealing with a person? Is it really the case that the only possible response to the threat of speciesism is to consider all living beings as belonging to one species? I do not think we can answer "yes" to either of these questions. The differentia specifica, the difference between a person and a non-personal being, despite its being a difference of kind rather than of degree, does not provide the ground for restricting the range of the moral duty merely to persons. In order to make personalism open onto the recognition of moral duties towards animals, we must depart from the Kantian justification of moral law based on the analysis of the law-giving will of the subject of morality. Instead, we need to analyze the axiological structure of the reality the human subject encounters while acting. 
Although the cognitive and moral phenomena in animals are absolutely fascinating, animals are incapable of transcending the centricity of their existence. They are self-conscious beings, but an animal is unable to identify itself with a self conceived of as ego or as the narrative center of its own animal subjectivity. Animals can experience emotions, and in some cases, they are capable of rational thinking, more than that, owing to their communication skills, they can even play or participate in a game. Still, they are incapable of producing a language that would comprise a grammar, while grammar is inherent to language. Animals are intentionally driven towards the objects of their desires, but incapable of experiencing second order desires, which, as Harry Frankfurt observes, make a person capable of relating to his or her volitions. While discovering a close relatedness between humans and animals, we cannot disregard the fact that only human beings can reflect on such phenomena and explore the ontological and axiological meaning of their capacity to reflect on these issues. Apparently, what distinguishes humans from other beings in this world is their recourse to the concepts of being and the good. Let's observe, against Hume's well-known idea, that in order to reflect on an entity or discuss it, humans need to transcend their own being, since persons are, metaphorically speaking, beings motivated by centrifugal rather than centripetal force, and they aspire to grasp the meaning of the phenomena outside them so as to arrange them into a meaningful whole.

\section{The Subject of Morality and the Object of Morality}

Interestingly, while morality as such is a phenomenon restricted to humans, it encompasses also nonhuman beings. Therefore, we need to keep the distinction between the "subject of morality," or the "agent" (who is always a person), and the object (or the addressee) of moral duty, which can be either a personal or a nonpersonal being. It is only understandable that among all nonpersonal beings, animals occupy a prominent position. Thus, in the tradition of St. Francis of Assisi, they are called our "lesser brethren."

The reason why we have moral duties towards animals is not exclusively our close relatedness to them, nor even a possible brotherhood between humans and animals. Such a justification of animal ethics would be tantamount to thinking in terms of speciesism, although the limits of the species would be broadened so as to include the beings related to humans. We need to seek an objective source of moral duty rather than derive obligation merely from our sympathy towards beings that are closely related to us. For that matter, Kant is right in saying that the grounds on which a human person must be treated as an end-in-itself and never merely as means is not the specific emotional bond with similar beings, but the fact that persons belong to the "kingdom of ends" (Kant 1987). Beings are "admitted" to this kingdom insofar as they exhibit moral autonomy, which consists in their being sovereign law-givers who find themselves bound by the categorical imperatives they have made. Kant's moral insight is cogent when he stresses that moral duty, in its nature, is unselfish. Yet his claim that the dignity of the person derives from the person's moral autonomy while moral autonomy presupposes human dignity seems problematic (Kant 1987). Unless we are dealing with a circular argument, there must be a gap in his understanding of the sources of moral duty.

The experience of moral duty becomes more understandable once we recognize that moral duty is actually founded on the "truth" about the value of the object or addressee, of our actions and attitudes. Value ethics, which explains that morality is human response (i.e., the response of a human being conceived of as person) to the recognition of what the truth about values is, fills the gap which Kant seems to have disregarded in his otherwise revolutionary ethics, which opened new prospects for moral philosophy. Indeed, Kant's categorical imperative may be enriched by its interpretation in the terms of the values ethics. 
The fundamental moral norm proposed by Karol Wojtyła commands respect for the person as person, and, as such, corresponds to the commandment of love for the neighbor. Yet in his philosophical works, Wojtyła includes a description of the essential elements of the truth about the person as they can be grasped by way of phenomenology. Briefly speaking, Wojtyła (1979) holds that the person is a being easily identifiable by his or her actions. Ethical cognitivism leads Wojtyła further to the formulation of a principle that is even more general than the personalist norm itself: He writes about the "normative power of truth" (Wojtyła 1979). In the context of this principle, whatever we know about the human being and the world is morally significant. Once recognized, the truth about the good is binding for the subject and obliges the subject to live according to this truth. As Pope John Paul II, Wojtyła published an encyclical letter on the foundations of morality and gave it a distinctive title: Veritatis Splendor. In it, he speaks about the splendor of truth, since truth has both theoretical and moral impact (Wojtyła 1979). However, it does not mean that recognition of truth as such makes a human being morally good. Rather, the point is that human beings can grow morally owing to their attitude to the knowledge they have grasped. It means that morality is accomplished within human conscience, in which the cognitive content about the state of affairs, once grasped by the subject, becomes the ultimate source of freely accepted and from now on binding moral imperative: Truth generates duty.

In his ethics, Wojtyła (1979) succeeds in overcoming the naturalistic fallacy, traditionally attributed to the objectivist ethics, yet his moral philosophy remains an ethics of objective goods, which is possible owing to the synthetic category of the "truth about the good," which he introduced into ethical discourse. A similar insight might be found in the thought of Antonio Rosmini, a 19th century Italian philosopher, who held that ethics rests on two principles: of being and of truth. According to Rosmini, morality is a separate act built upon a recognition of the truth about being according to the axiological order of being (Antonio Rosmini 1988). Although Rosmini himself does not focus on the value of animals, it remains without doubt that his ethics, which explains moral duty by the openness of a human subject to the truth about the real world, remains also open to the truth about the ontological and axiological status of animals.

Thus, moral duty can be stated not only in relation to human beings. An epistemologically grounded conception of personalist ethics is capable of incorporating the present-day knowledge of the value of the lives of animals and of their subjectivity without, however, diminishing the status of humans, who remain the only moral agents in the realm of being and thus, the exclusive subjects of morality, which implies that they should embrace animals with even deeper care and take responsibility for their "lesser brethren."

\section{Animal Ethics as a Pressing Issue for Humanism}

Reflection on the responsibility of humans for the fate of animals is becoming an increasingly pressing issue, since the development of modern civilization was a one-way process, favoring the existence of human beings exclusively. The victims of that tendency have been animals.

Had it not been for the lesson taught by modern humanism, the ideal of care for the welfare of animals might not have emerged in the history of morals. Thus, the criticism of modernity must not be targeted at the humanism it promotes; rather, it needs to focus primarily on the rationalist interpretation of the humanist ideas, which, not infrequently, takes the arrogant form of speciesist exclusivism. Such a revision of humanism, in a poetic condensation, can be found in the poems of Gary Snyder, an outstanding representative of the Beat Generation. 
$[\ldots]$

Is man most precious of all things?

-then let us love him, and his brothers, all those.

Fading living being -

North America, Turtle Island, taken by invaders.

Who wage war around the world.

May ants, may abalone, otters, wolves and elk.

Rise! And pull away their giving

From the robot nations.

Solidarity. The People.

Standing Tree People!

Flying Bird People!

Swimming Sea People!

Four-legged, two-legged people!

Referring to animals as man's brothers, the contemporary poet resembles St. Francis, yet the dramatic tone of Snyder's poetry differs from the gentleness of the Assisi poet's verse. St. Francis did not have the experience of the world in which numerous animal species have become extinct, and breeding of useful animals has been industrialized, bringing suffering to billions of living creatures treated as products, while others have been subjected to cruel experiments devised to forward the progress of civilization. Snyder's rebellious appeal must resound and be heard because the ideal of St. Francis has been lost and the modern world has turned into its negation.

Today, however, the rhetoric of rebellion and animal liberation is no longer a humanist one. In contradistinction to some animal ethicists who speak of man exclusively in terms of "animality," dividing living creatures into "human" and "nonhuman" animals, Snyder speaks about living beings: plants, four-legged, and two-legged animals, in terms of "humanity." What he means in both cases is kinship, not identity. The poet seems to be saying that the question of human dignity-"Is man most precious of all things?"-calls, in the first place, for the recognition of the dignity of the realm of life, of which man partakes, his contribution being his ability to ask questions, as well as his solidarity with all creatures and rebellion against injustice.

\section{Works Cited}

Immanuel, Kant. Groundwork of the Metaphysic of Morals. "The Moral Law." Kant's Groundwork of the Metaphysic of Morals translated and analysed. Trans. H.J. Paton. London: Hutchinson, 1987.95-96.

Antonio Rosmini. Principles of Ethics. Trans. T. Watson and D. Cleary. Leominster: Fowler Wright Books, 1988. 82-83.

Gary Snyder. "Mother Earth: Her Whales." Turtle Island. New York: New Directions 1974. 48.

Karol Wojtyła. The Acting Person. Trans. A. Potocki. Dordrecht: D. Reidel Publishing Company, 1979. 161-62.

Antonio Rosmini. Principles of Ethics. Leominster: Fowler Wright Books, 1988. 